SVETLA STOILOVA, Ph.D. ${ }^{1}$

(Corresponding author)

E-mail: stoilova@tu-sofia.bg

VESELIN STOEV, M.Sc. Eng. ${ }^{1}$

E-mail: stoev@tu-sofia.bg

${ }^{1}$ Technical University of Sofia, Faculty of Transport

8 KI. Ohridski Blvd., 1000, Sofia, Bulgaria
Traffic Policy

Original Scientific Paper

Submitted: 19 Apr. 2016

Accepted: 22 Sep. 2016

\title{
METHODOLOGY OF TRANSPORT SCHEME SELECTION FOR METRO TRAINS USING A COMBINED SIMULATION-OPTIMIZATION MODEL
}

\begin{abstract}
A major problem connected with planning the organization of trains in metros is the optimization of the scheme of movement, which determines the routing and the number of trains. In this paper, a combined simulation-optimization model including four steps is proposed. In the first step, the train movement has been simulated in order to study the interval between the trains according to the incoming passenger flows at the stations. The simulation model was elaborated using the ARENA software. The results were validated through experimental observations. Using the results obtained from simulations in the second step the correlation between the observed parameters - the incoming passengers and the interval between trains - has been studied. Recent research has established a non-linear relationship between the interval of movement, incoming passengers at the station and passengers on the platform. The third step defines the variant schemes of transportation. The fourth step presents the optimal choice of transportation of trains in metros based on linear optimization model. The model uses the regression obtained in the second step. The practicability of the combined simulation-optimization model is demonstrated through the case study of Sofia's metro in two peak periods - morning and evening. The model results and the real situation have been compared. It was found that the model results are similar to the real data for the morning peak period but for the evening peak period it is necessary to increase the number of trains.
\end{abstract}

\section{KEY WORDS}

metro; simulation; ARENA; linear optimization; train; station; passenger;

\section{INTRODUCTION}

Designing a transport scheme of the movement of trains in metro includes the routing and the number of trains for each route. A metro line is an infrastructural track which connects the starting point with the finishing point and has a definite number of stations. A metro route is an organization of train movements between the starting and the finishing station and it consists of one or more metro lines. In most metro networks the metro lines coincide with the routes. In this case the problem is limited to determining the number of trains. The infrastructure features of the metro network of such a metro as the one in Sofia, allow the routes not to coincide with the metro lines. Therefore, in these cases, an important task for the organization of transport in a metro is to determine the optimal scheme of movement of metro trains in the metro network. The transport scheme includes the metro routes in a metro network.

Determining the optimal scheme of the movement depends on the size of the incoming passenger flows at the stations, the passengers between two adjacent stations, how full the trains are, the needed frequency of services, the available rolling stock.

The observation of incoming passenger flows in metro stations, the embarkation and disembarkation of passengers, the movement of trains in real time are important for the decision-making process related to the organization of transport but it is a difficult task because of the special status of the metro. For this purpose it is appropriate to use simulation modelling as a tool for investigating the passenger flows, the interval of the trains, the frequency of services and for identifying the correlations between them. It is necessary to determine the scheme of movement of trains.

Simulation modelling is the subject of research for metro networks. In [1] the authors have developed a simulation model of movement of trains using MATLAB software. In [2] a simulation model of the metro network has been developed including a group of four successive stations for train simulation and calculation of certain parameters for the system performance. In [3] simulations have been made using the ARENA software for three metro stations on the metro of Montreal. The research shows that the incoming passengers can be represented by the Poisson distribution.

Metro stations, as major element in the organization of the movement of trains are subject to modelling by applying the queueing theory with Poisson inflow of 
passengers and exponential distribution of the time of service, [3, 4, 5, 6]. In [7] a simulation model which studies a group of four consecutive stations was developed, to simulate the movement of the trains. In [8] a simulation software has been applied based on the programming language " $\mathrm{C}++$ " for simulating metro traffic at different times of the day and in different technological situations. In [9] simulation models are created by using software VISSIM which serves to analyse the train boarding and alighting and the speed of trains and delays.

The optimization models for the interval of train movement on the metro are elaborated in $[3,10]$ in order to reduce the average travel duration for passengers. Some authors do simulation modelling of emergency situations that are related to a rapid exit of passengers from the metro station. In [11] the passengers in the stations, the boarding and alighting have been investigated for the evacuation purposes and a simulation model for Beijing's metro in China has been developed, where five evacuation scenarios have been set according to different specifications. In [12] the authors have presented a simulation-based DTA model, which considers combined travel modes including private cars, metro, buses and bicycles. The framework consists of a multi-modal supply network and a demand simulator. The interaction between mode-route choice and traffic assignment is investigated. The traffic assignment procedure is established through a time-dependent shortest-path algorithm.

The optimization of the routing of trains in the metro has not been sufficiently investigated. Examining the issue for other types of public transportation it has been established that an important criterion for the organization of transport is minimizing the transport costs with the existing rolling stock in service and meeting the needs for trips on sections of the transport network [13, 14].

The aim of the present paper is to propose an integrated approach based on simulations and optimization of the transport process to determine the scheme of transportation of metro trains according to incoming passengers and the interval of train movement. In this study the simulation modelling is used to investigate the passenger flows and the train movement interval in the metro so as to determine the necessary frequency of services for passengers. The optimization method is applied to determine the routes and the number of trains in the metro. Determining the optimal scheme of the movement of trains in a metro is an important task for transport operators in order to ensure that passengers' needs are satisfied with minimal transport costs. The object of the study is the metro network of Sofia metro.

\section{RESEARCH METHODOLOGY}

The methodology includes four steps. In the first step the train movement is simulated in order to study the interval between the trains according to the incoming passenger flows in stations. Using the results obtained from the simulations in the second step the correlation between the observed parameters (the incoming passengers and the interval between the trains) is studied. The third step includes the definition of variant schemes of transportation. The fourth step presents a linear optimization model by the criterion of minimum train kilometres to determine the number of trains for each variant scheme. The optimal choice of transportation in a metro is based on the selection of a scheme with a minimum of optimization criteria. The scheme of methodology is presented in Figure 1.

\subsection{Step 1: Simulation model of the movement of metro trains}

The main parameters to investigate by a simulation model are the duration of the interval of the movement, i.e. the number of trains in one hour and the volume of incoming passengers.

The main parameters for modelling are divided into two processes working in parallel. In the first process the passenger flows between stations are defined. In the second process the train movements between metro stations and their stay there are defined. The second process includes also the passengers boarding/alighting the train and leaving the station.

The parameters of the first process are:

- the inflow of passengers in the stations. Poisson distribution was adopted in the research. The maximum value of the inflow depends on the capacity limits of the platform, elevators, escalators, validators, and others elements in the stations. It is necessary for the incoming passengers for the period equal to the interval of movement of the trains not to exceed the maximum capacity of passengers on the platform.

- passenger flows between all stations included in the model. The passenger flow from station $i$ is the amount of passengers who departed from the station to other stations, i.e.:

$P_{i}=\sum_{j=i+1}^{n} P_{i j}$

where: $i=1, \ldots, n$ is the number of stations, $P_{i j}$ is the passenger flow from station $i$ to station $j$, pass./h.

The passenger flows from one station to other stations located beyond it on the route of the train can be presented as discrete values by a cumulative function, $[15,16,17]$ :

$$
\begin{aligned}
F\left(P_{i}\right)= & \operatorname{DISCRETE}\left(c_{i 1} \cdot P_{i 1}+c_{i 2} \cdot P_{i 2}+\ldots+\right. \\
& \left.+c_{i j} \cdot P_{i j}+\ldots+c_{i n} \cdot P_{i n}\right)
\end{aligned}
$$




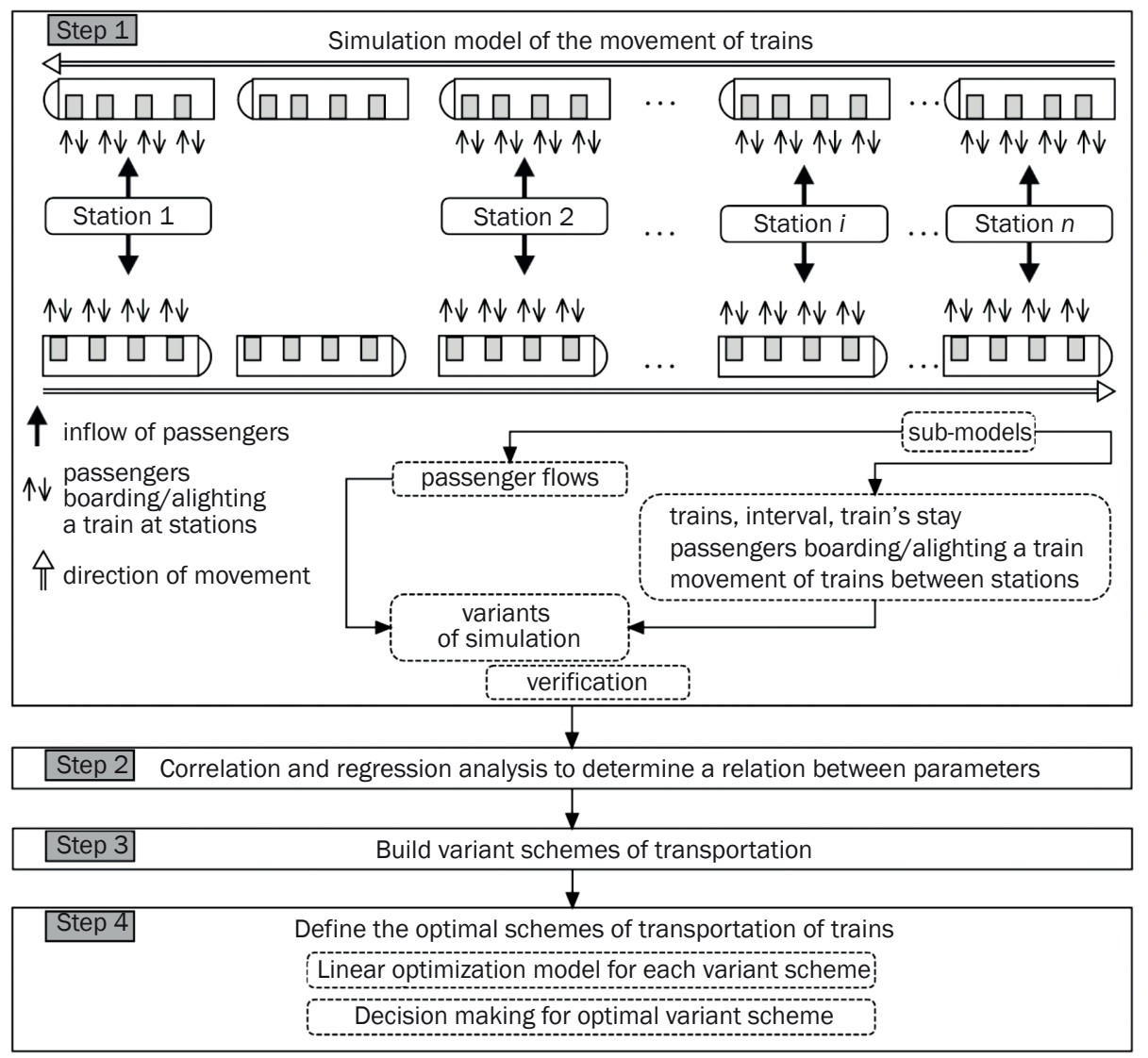

Figure 1 - Scheme of methodology

where: $P_{i 1}$ is the number of passengers going to the next metro station (the first one after the metro station where the trip started, pass./h; $P_{\text {in }}$ is the number of passengers that go to the last station on the route of the train, pass./h.

Coefficient $c_{i j}$ shows the probability for the passengers who have started their journey at metro station $i$ to go to station $j$. For probabilities $c_{i j}$ the following relationship is valid:

$$
c_{i j} \geq c_{i, j-1}
$$

The probability for the passengers to disembark at the next (first) station, compared to the origin of the journey is presented by a cumulative function $\left(c_{i 1}=0.1\right)$, but for each subsequent station this probability increases compared to the previous station. For the last metro station $c_{i n}=1$, that is, all passengers must leave the train.

The parameters of the second process are:

- The trains are set as a constant value depending on the period of the simulation and the interval between them;

- The length of the stay of trains in each station is set as a constant value; its value for all stations being $30 \mathrm{~s}$.

- The movement of trains between stations is a constant value, as its values for different inter-stations are different and depend on the time of travel.
- The time for the passengers to leave the metro station after the arrival of the train in the study was adopted by Exponential distribution and its average value is the same for all stations in a simulation model, i.e. one minute.

For modelling the movement of trains it is necessary that the following condition is met:

$$
P_{i j}^{q}=A \cdot \alpha
$$

where: $P_{i j}^{q}$ are the passengers in section $q$, formed between two adjacent stations $i$ and $j$; the duration of the interval between trains, pass./train; $A$ is the capacity of the train (seating and standing places); $q=1, \ldots, \mathrm{n}-1$ is the number of sections; $n$ is the number of stations; $\alpha$ is the coefficient of usage of places which is different for different periods of the day; $\alpha=0.9$ for a peak period.

The movement interval is determined by the following restrictions:

- The maximum interval between the trains is $I_{\max }=10 \mathrm{~min}$. This interval is the maximum one for satisfying the transport needs on the metro, [17, 18].

- The minimum interval between the trains $I_{\text {min }}$ running at peak periods depends on the capacity of the metro and the existing rolling stock. On the Sofia metro the maximum capacity is determined for an interval $I_{\min }=1.5 \mathrm{~min}$ between trains, but due 
to the lack of the necessary rolling stock, the minimum interval of movement in the peak period is $3 \mathrm{~min}$.

$I_{\min } \leq I_{m} \leq I_{\max }$

The following constraint is valid for an average duration $T_{p}^{\text {exit }}$ for the exit of the passengers from the metro station, after disembarking the train:

$T_{p}^{\text {exit }} \leq I_{\min }$

\subsection{Criteria for validation of the simulation model}

To make an assessment of the extent to which the simulation model reflects the actual processes in the investigated system it is necessary to perform a validation, $[15,18,19,20]$. The study applied the following criteria for validation:

1) The mean absolute percentage error, [20]. This criterion presents the average variation in estimates resulting from modelling to the actual values. It is defined by the formula:

$S_{\text {MAPE }}=\frac{\sum_{i=1}^{n} \frac{\left|x_{i}-y_{i}\right|}{x_{i}}}{n} \cdot 100 \%$

where: $X_{i}$ are the actual (real) values of the observed parameters of research process; $Y_{i}$ are the values obtained through simulation; $n$ is the number of investigated cases, $i=1, \ldots, n$.

To assess the degree of validation by the mean absolute percentage error the scale introduced in [20] can be used: $s_{M A P E}<10 \%$ - Highly accurate; $10 \% \leq s_{M A P E}<20 \%$ - Good; $20 \% \leq s_{M A P E}<50 \%$ - Reasonable; $s_{\text {MAPE }} \geq 50 \%$ - Inaccurate.

2) Coefficient of determination $\left(R^{2}\right)$. This factor indicates what part of the variation of the simulation model is due to differences in experimental values. For the evaluation of the validation is used the scale introduced in [18] can be used: from 0 to 0.3 - low; from 0.3 to 0.7 - average; over 0.7 - high.

3) Nash-Sutcliffe efficiency (NSE), [20]. The Nash-Sutcliffe efficiency determines the relative magnitude of the residual variance compared to the measured data variance. The coefficient NSE indicates how well the plot of observed versus simulated data fits the $1: 1$. NSE is determined by the formula as follows:

$N S E=1-\left[\frac{\sum_{i=1}^{n}\left(X_{i}-Y_{i}\right)^{2}}{\sum_{i=1}^{n}\left(X_{i}-\bar{X}\right)^{2}}\right]$

where: $\bar{X}$ is the average number of the actual (real) values of the observed parameters of research process. The coefficient NSE ranges between $-\infty$ and 1
(1 inclusive), with $N S E=1$ being the optimal value. Values NSE between 0 and 1 are generally viewed as acceptable levels of performance, whereas values $N S E<0.0$ indicate that the mean observed value is a better predictor than the simulated value, which indicates unacceptable performance.

In [20] the following estimates for the efficiency ratio are given: $0.75<N S E \leq 1$ - Very good; $0.65<N S E \leq 0.75$ - Good; $0.5<N S E \leq 0.65$ - Satisfactory; NSE $\leq 0.5$ - Unsatisfactory.

4) Standard deviation ratio $R S R$. $R S R$ ratio combines the standard error of the residuals (the difference between the real and simulated values) and standard deviation of the experimental data. RSR ratio is defined by the formula as follows [20]:

$$
R S R=\frac{\sqrt{\sum_{i=1}^{n}\left(X_{i}-Y_{i}\right)^{2}}}{\sqrt{\sum_{i=1}^{n}\left(X_{i}-\bar{X}\right)^{2}}}
$$

In [20] the following estimates for the coefficient of standard deviation $R S R$ are shown: $0<R S R \leq 0.5$ - Very good; $0.5<R S R \leq 0.6$ - Good; $0.6<R S R \leq 0.7$ - Satisfactory; RSR>0.7 - Unsatisfactory.

\subsection{Step 2: Investigation of the relationships between the parameters}

The developed simulation model of the transportation process and simulations which have been carried out make it possible to form a database and do additional research. The database includes the following information for each of the investigated metro stations:

- Input: incoming passengers; interval of the metro trains;

- Output information from the simulation modelling: average number of passengers waiting on the platform for the train arrival.

The organization of transport in the metro is related to determining the interval between trains. Mainly, it depends on the incoming passenger flow.

The database allows the study of the dependence on the interval of movement of trains from the incoming passenger flows as well as from the average number of passengers waiting on the platform for the train arrival.

In this step, using the established database the correlation and regression analysis are applied to investigate the relationships between observed parameters and the type of the function, i.e.

$P_{p}=f\left(\lambda, I_{m}\right)$

where: $P_{p}$ is the average number of passengers waiting on the platform for the train arrival, pass./train; $\lambda$ are the incoming passengers in the metro station, pass./ $\mathrm{h} ; I_{m}$ is the interval between trains, min. 
The relationship for the interval of the trains is obtained by transforming Formula 10.

$$
I_{m}=f\left(\lambda, P_{p}\right)
$$

The determination of this dependence would allow the calculation of the necessary interval of the trains for the station using the given values of the incoming passengers in the metro station and the average number of passengers waiting on the platform for the train arrival.

\subsection{Step 3: Build variant schemes of transportation}

When forming the scheme for the transportation by trains, the metro stations are defined as: initial (final) station on the route - it is possible to reverse the direction of movement of the trains; intermediate station - only alighting and boarding of passengers is performed; transfer station - changing of the route on the same platform can be done; transfer node - a complex of metro stations with private infrastructure. They are connected with tunnels, escalators, stairs, walkways or other devices, such as transferring the passengers from one route to another.

Let $i=1, \ldots, n$ be the number of stations on the metro network. Let $z=1, \ldots, Z$ be the number of metro stations that can form metro routes, i.e. change direction. The number of sections which are formed between the metro stations are $j=1, \ldots, Z-1$.

The value of interval $I_{m_{j p}}$ is determined for each station $p$ of section $j$ depending on the passenger flow and the number of passengers on the platform.

Interval $I_{m_{j}}$ is determined for each section $j$. It is formed by the minimum value of the intervals of stations in the section, i.e.:

$I_{m_{j}}=\min _{p=1, \ldots, P}\left\{I_{m_{j p}}\right\}$

where: $p=1, \ldots, P$ is the number of stations in section $j ; I_{m j p}$ is the interval determined through the relationship received by using correlation and regression analysis in step 2.

The station which fulfils the condition is called restrictive in study [10]. This station has the largest flow of incoming passengers in the section, i.e.:

$$
P_{m_{j}}=\max _{p=1, \ldots, P}\left\{P_{m_{j p}}\right\}
$$

where: $P_{m j p}$ is the incoming passenger flow for station $p$ from section $j$, pass./h

For the interval of movement, defined for each section $j$, Condition 5 must be met.

The interstation with a maximum passenger flow is determined for each section $j$. These interstations in the study are called restrictive.

For the metro network $s$ schemes of servicing by metro trains are designed to meet the condition of movement of metro trains between stations that have the necessary infrastructure for this.

\subsection{Step 4: Optimization of the scheme of movement of metro trains}

The aim is to optimize the movement of trains by routes, so that for each $s$ variant scheme the following optimization function is fulfilled:

$R_{f}=\sum_{k=1}^{K} x_{k f} \cdot I_{k f} \rightarrow \min$

where: $k=1, \ldots, K$ is the number of routes in the variant scheme of the movement of trains on the metro; $x_{k f}$ is the number of trains for route $k$, train/h; $x_{k}$ is the length of route $k, \mathrm{~km} ; f$ is the number of variant scheme.

The scheme with the minimal value of train kilometres is optimal.

$R_{o p t}=\min \left\{R_{1}, \ldots, R_{f}\right\}$

The optimization function is applied separately for each variant scheme.

The restrictive conditions are:

1) Ensuring the necessary frequency of services for passengers:

$$
\sum_{k=1}^{K} x_{k f} \cdot \gamma_{j k} \geq \frac{60}{I_{m j}}
$$

where: $\gamma_{j k}$ is the coefficient that shows the routes which pass a given section; $\gamma_{j k}=1$, if a train of route $k$ services section $j ; \gamma_{j k}=0$, otherwise.

Condition 16 shows that the number of trains in section $\mathrm{j}$ must not exceed the number determined according to $I_{m_{j}}$, which accounts for the maximum inflow in the section. $I_{m_{j}}$ is determined using Formula 11 according to a predefined relationship established by using a correlation and regression analysis in step 2 .

2) If for a given section the station with a maximum incoming passenger flow is a transfer station and more than two routes pass through, the following condition is valid:

$$
\frac{1}{r} \cdot \sum_{k=1}^{K} x_{k f} \cdot \gamma_{j k} \geq \frac{60}{I_{m_{j}}}
$$

where: $r$ is the number of outgoing routes from the station.

3) Satisfying the maximum passenger flow between two stations in the section.

$\sum_{k=1}^{K} x_{k f} \cdot \gamma_{j k} \cdot a_{k} \cdot \alpha_{k} \geq P_{j}$

where: $a_{k}$ is the number of seating and standing places on a train from route $k ; \alpha_{k}=0.9$ is the coefficient of utilization of seats on a train from route $k, P_{j}$ is the maximum passenger flow between two stations for section $j$, pass./h. 
4) Realization of organization of train traffic with the available compositions in exploitation:

$$
\sum_{k=1}^{K} x_{k f} \leq W
$$

where: $W$ is the number of available compositions in exploitation.

5) The decision has to be positive and integer:

$$
x_{k f} \geq 0, x_{k f} \text {-integer } ; \forall k=1, \ldots, K ; \forall f=1, \ldots, F
$$

The elaborated optimization model can be applied for each peak and other period separately.

\section{EXPERIMENTAL WORK AND RESULTS: A CASE STUDY FOR THE SOFIA METRO}

\subsection{Simulation modelling}

For modelling the transport process on Sofia metro we have included stations with large passenger flows - Lyulin, Konstantin Velichkov, Opalchenska, Serdika, Sofia University, Vasil Levski Stadium, G.M. Dimitrov, Mladost 1, and metro station Slivnitsa, near which there is the depot, and all metro routes begin and end there.

The capacity of the train for Sofia metro is 140 seating and 930 standing places and the total length of the train is $83 \mathrm{~m}$. This capacity is consistent with the total length of the platform (104 m).
The simulation model for the movement of the train is elaborated by using ARENA ["Arena Enterprise Suite Academic" Version 14.0. by Rockwell Software]. The elements of the simulation model for metro station MS1 in ARENA are presented in Figure 2 and Figure 3.

The modelling is carried out by using the modelling language SIMAN and an animation system. Blocks are also used for modelling and they connect to each other in accordance to the relationships as well as the operations in the studied system. The block modules are presented in Table 1.

The research was made by real passenger flows and interval between trains for morning and evening peak periods in a duration of one hour. The parameters are shown in Table 2. The passengers were varied by a step of 15 passengers to an increase of 300 passengers within the fluctuation of the internal hour irregularity. The total number of simulations is 189 .

To validate the simulation model of the transport process on the metro, experimental observations in the peak period 07:00-9:30 were made and the maximum number of passengers waiting for a train on the platform was counted. With the simulation model, ninety simulations for the same period were carried out to make a comparison with the experimental observations. Table 3 shows the comparison of the indicators of validation for the simulations and experimental observations.

Given the results of the coefficients of validation it can be concluded that the developed simulation model adequately describes the real processes and

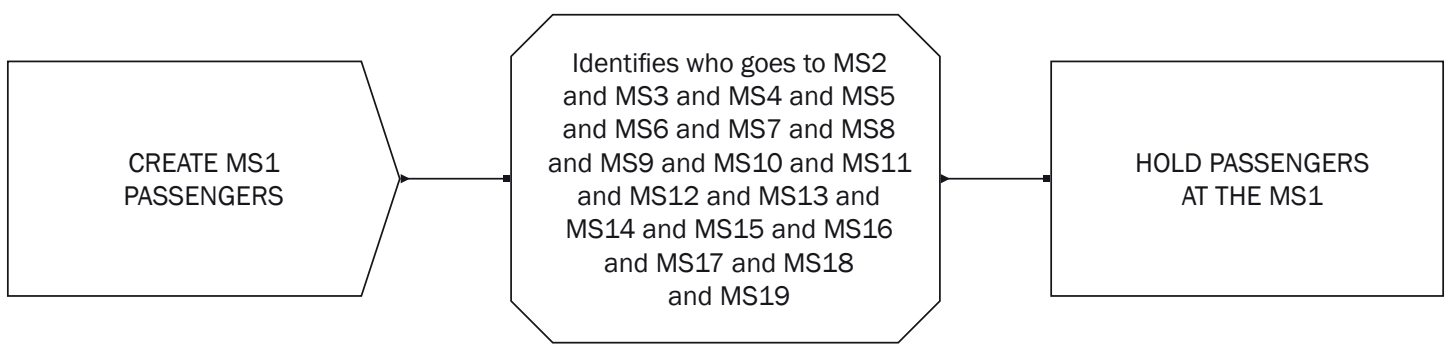

Figure 2 - Part of the simulation model for creating the departure passenger flow (pick up passengers from MS1)

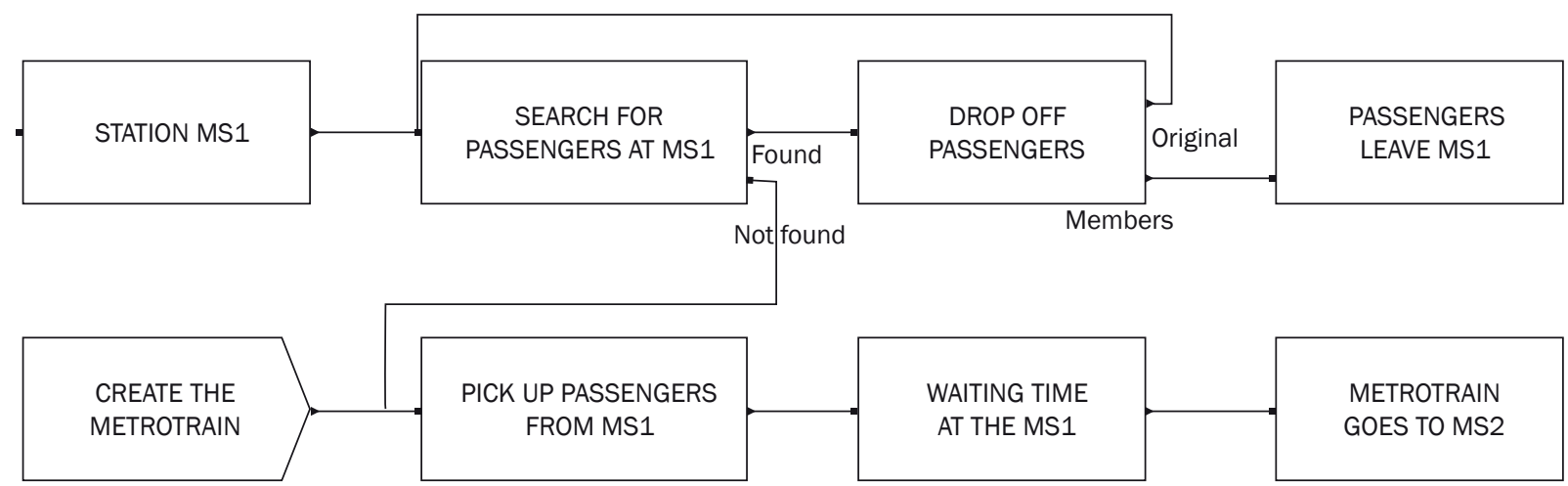

Figure 3 - Part of simulation model for departure of the train, boarding and alighting of passengers at the initial station 
Table 1 - Modules in ARENA

\begin{tabular}{|c|l||}
\hline Block module & \multicolumn{1}{|c||}{ Function } \\
\hline \hline Create & Establishment of: passengers; train \\
\hline Assign & Probability distribution of passenger's correspondence \\
\hline Hold & Passengers waiting on the platform \\
\hline Station & Create a process of alight and board of passengers in the metro station \\
\hline Search & Search of passengers in the train that go down to the metro station \\
\hline Drop-off & Alighting passengers \\
\hline Pickup & Embarking passengers on train \\
\hline Delay & Stay of the train in station \\
\hline Route & Time to travel between two adjacent stations \\
\hline Dispose & Final metro station \\
\hline
\end{tabular}

Table 2 - Real passenger flows and intervals by stations

\begin{tabular}{||l|c|c|c|c|c|c||}
\hline & \multicolumn{7}{|c||}{ Number of passengers per hour by stations } \\
\hline From - To & $6: 00-7: 00$ & $7: 00-8: 00$ & $8: 00-9: 00$ & $9: 00-10: 00$ & $10: 00-11: 00$ & $13: 00-14: 00$ \\
\hline Real interval, min & 4 & 3 & 3 & 3.5 & 4.5 & 4.5 \\
\hline \hline Slivnitsa & 750 & 1,576 & 1,669 & 752 & 555 & 540 \\
\hline Lyulin & 1,120 & 2,738 & 3,162 & 1,571 & 961 & 877 \\
\hline Konstantin Velichkov & 510 & 1,635 & 2,233 & 1,278 & 856 & 838 \\
\hline Opalchenska & 152 & 615 & 1,175 & 775 & 716 & 1,524 \\
\hline Serdika & 140 & 928 & 956 & 862 & 958 & 1,618 \\
\hline Sofia University & 220 & 946 & 1,552 & 1,091 & 914 & 2,224 \\
\hline Vasil Levski Stadium & 110 & 830 & 1,020 & 665 & 580 & 1,187 \\
\hline G.M. Dimitrov & 280 & 1,431 & 2,767 & 1,664 & 1,228 & 1,466 \\
\hline Mladost 1 & 498 & 1,253 & 1,771 & 1,317 & 991 & 879 \\
\hline
\end{tabular}

Table 3 - Comparison of indicators for simulation and experimental observations

\begin{tabular}{|c|c|c|c|c|c||}
\hline Comparison & Number of cases & $S_{\text {MAPE }}$ & NSE & $R S$ & $R^{2}$ \\
\hline \hline Simulation - Experiment & 90 & $18 \%$ & 0.70 & 0.55 & 0.58 \\
\hline Estimates & & Good & Good & Good & Average \\
\hline
\end{tabular}

it can be assumed that the average number of passengers waiting for a train on the platform in the peak period is 80 passengers.

\subsection{Correlation and regression analysis}

Using the data obtained from simulations we conducted the correlation and regression analyses to study the relationship between passengers and interval between trains. We studied linear and non-linear functions.

In the research the following non-linear relationship has been obtained:

$P_{p}=-0.001 \lambda+0.007 \lambda I_{m}, R^{2}=0.79$

where: $P_{p}$ is the average number of passengers waiting on the platform for the train arrival, pass./train; $\lambda$ is incoming passengers in the metro station, pass./h; $I_{m}$ is the interval between trains, min.
Taking into account the maximum interval between trains in Sofia metro the regression Equation 21 is valid when:

\section{$1.5 \leq I_{m} \leq 15$}

The relationship for the interval of the trains is obtained by transforming Equation 21:

$I_{m}=0.143+142.85 \frac{P_{p}}{\lambda}$

Formula 23 is used when: $P_{p}<\lambda ; \lambda>0 ; P_{p} \geq 0$. The values are valid when Condition 22 is satisfied. Formula 23 is used for the station with maximum incoming passengers.

The number of passengers on the platform cannot exceed the maximum capacity of the platform. If it is assumed that the area of one passenger is $1 \mathrm{~m}^{2}$, and the bay area is $478 \mathrm{~m}^{2}$, it can be assumed that the maximum number of passengers on the platform for 
an interval of metro trains is 400 pass./train. In determining the maximum number of passengers on the platform only the effective area is taken into account, i.e. without the area for benches, columns and others. Given these conditions it can be accepted that $P_{p} \leq 200$ pass./train.

Figure 4 shows a nomogram to determine the interval depending on the incoming passenger flows. Using this nomogram the interval between trains can be determined when the station with the maximum number of incoming passengers is set.

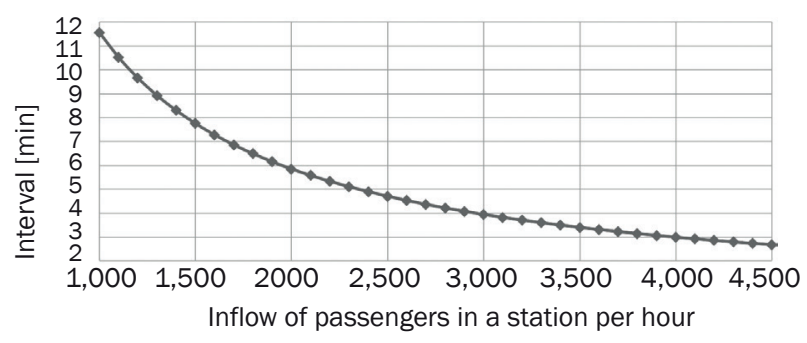

Figure 4 - Interval between metro trains according to different incoming passengers per hour

\subsection{Variant schemes}

Metro routes can be formed between stations that have the necessary infrastructure to be initial/final stations in the scheme of movement. Figure 5 shows the investigated sections and variant schemes for Sofia metro.

The passengers can change the metro routes in transfer stations and transfer nodes. In transfer stations the change of metro routes is done on the same platform. Transfer node is a complex of metro stations with private infrastructure which are connected with tunnels, escalators, stairs, walkways or other devices.

Given the initial (final) and transfer stations, the metro network is divided into four sections, depending on its infrastructure features to reverse the direction of movement of trains.
The first variant scheme 1 corresponds to the existing organization of the movement of trains in Sofia's metro and includes two routes $X_{1}$ and $X_{2}$. In the second variant scheme 2 the routes $X_{1}$ and $X_{2}$ are reversed. The third variant scheme 3 includes three routes, the first two are similar to those in Scheme 1, and the third route $X_{3}$ operates in parallel with the other two routes in the section with the greatest passenger flows.

\subsection{Approbation of the linear optimization model}

The optimization model was applied to the proposed three variant schemes, given the average number of passengers waiting on the platform to be 80 . This value was determined from observations by means of which it has been established that the maximum number of passengers waiting on the platform for the interval between trains at the peak period is about 160 passengers. Each of the variant schemes is examined for two peak periods - morning and evening, in the duration of one hour. This is necessary because of different characters of passenger flows for these periods. Table 4 shows the number of passengers in the sections, the inflow of passengers and the interval determined by Formula 23 for the restrictive station in each section. These parameters are used in the optimization model. Table 5 shows the results of the optimization of the number of trains and train-kilometres for each of the examined schemes. Table 6 shows the interval of movement, the number of trains for both peak periods according to the methodology and the current situation on Sofia metro.

The first section has a maximum number of passengers and determines the interval between trains. The number of trains for each variant scheme for both peak periods is the same. The results show that for both peak periods the third route $X_{3}$ is not necessary. The optimal is variant scheme 1 for both peak periods. This scheme coincides with the existing organization of the metro routes in Sofia metro. For the evening peak period it is necessary to increase the number of

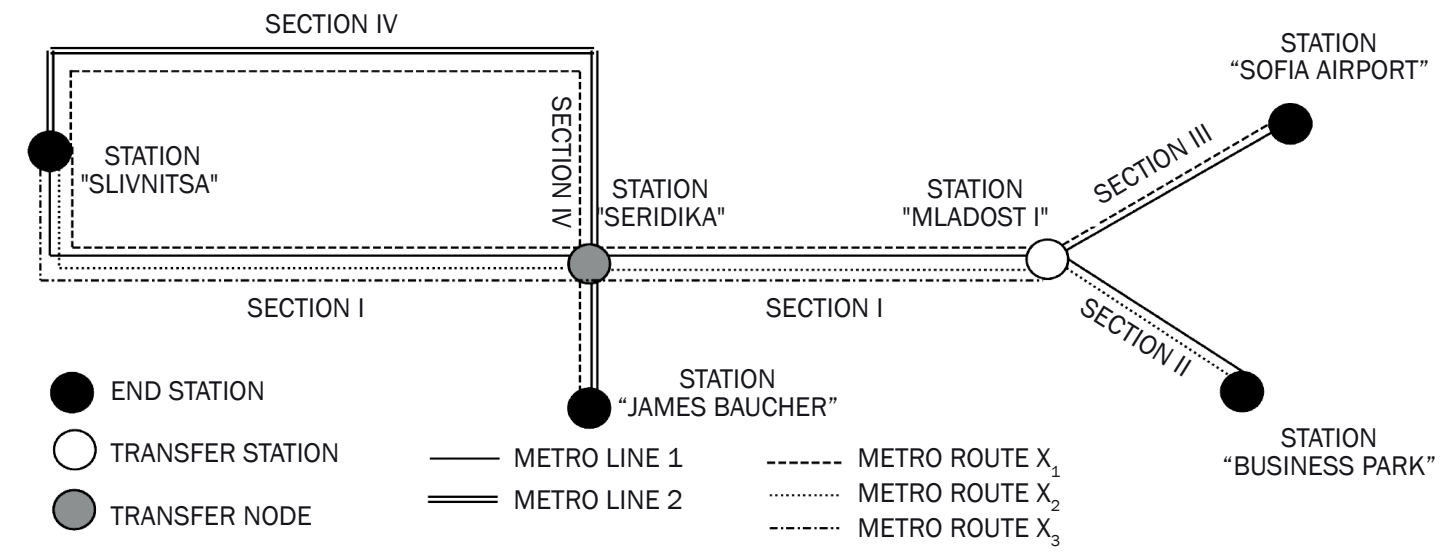

Figure 5 - Variant schemes of transportation 
Table 4 - Parameters of the optimization model by sections

\begin{tabular}{|c|c|c|c|c|c|c||}
\hline \multirow{2}{*}{ Section j } & \multicolumn{3}{|c|}{ Morning peak period } & \multicolumn{3}{c||}{ Evening peak period } \\
\cline { 2 - 7 } & $P_{j}$, pass./h & $P_{m_{j}}$, pass./h & $I_{m_{j}}$, min. & $P_{j}$, pass./h & $P_{m_{j}}$, pass./h & $I_{m_{j}}$, min. \\
\hline \hline I & 8,230 & 3,162 & 3.75 & 10,377 & 4,627 & 2.44 \\
\hline II & 6,493 & 1,771 & 6.60 & 8,560 & 2,213 & 5.30 \\
\hline III & 7,053 & 1,683 & 7.00 & 9,213 & 2,213 & 5.30 \\
\hline IV & 7,727 & 1,768 & 6.60 & 8,906 & 1,796 & 6.5 \\
\hline
\end{tabular}

Table 5 - Comparison of results for the variant schemes

\begin{tabular}{||l|l|c|c||}
\hline \multicolumn{2}{|c|}{} & Morning peak period & Evening peak period \\
\hline \hline \multirow{3}{*}{ Variant scheme 1 } & Number of trains per hour $X_{1}$ & 10 & 12 \\
\cline { 2 - 4 } & Number of trains per hour $X_{2}$ & 10 & 13 \\
\cline { 2 - 4 } & Train kilometres & 463 & 572.1 \\
\hline \multirow{3}{*}{ Variant scheme 2 } & Number of trains per hour $X_{1}$ & 10 & 12 \\
\cline { 2 - 4 } & Number of trains per hour $X_{2}$ & 10 & 13 \\
\cline { 2 - 4 } & Train kilometres & 463 & 12 \\
\hline \multirow{3}{*}{ Variant scheme 3 } & Number of trains per hour $X_{1}$ & 10 & 13 \\
\cline { 2 - 4 } & Number of trains per hour $X_{2}$ & 10 & 0 \\
\cline { 2 - 4 } & Number of trains per hour $X_{3}$ & 0 & 572.1 \\
\cline { 2 - 4 } & Train kilometres & 463 & 12.6 \\
\hline
\end{tabular}

Table 6 - Comparison of results with current situation

\begin{tabular}{|c|c|c|c|c|c|c|}
\hline & & & Section I & Section II & Section III & Section IV \\
\hline \multirow{4}{*}{$\begin{array}{c}\text { Morning } \\
\text { peak period }\end{array}$} & \multirow{2}{*}{ Current situation } & $I_{m}, \min$ & 3.75 & 6.06 & 6.06 & 6.60 \\
\hline & & Number of trains per hour & 20 & 10 & 10 & 10 \\
\hline & \multirow{2}{*}{ By methodology } & $I_{m}, \min$ & 3.75 & 6.60 & 7.00 & 6.60 \\
\hline & & Number of trains per hour & 20 & 10 & 10 & 10 \\
\hline \multirow{4}{*}{$\begin{array}{c}\text { Evening } \\
\text { peak period }\end{array}$} & \multirow{2}{*}{ Current situation } & $I_{m}, \min$ & 3.50 & 7.00 & 7.00 & 7.00 \\
\hline & & Number of trains per hour & 18 & 9 & 9 & 9 \\
\hline & \multirow{2}{*}{ By methodology } & $I_{m}, \min$ & 2.44 & 5.30 & 5.30 & 6.50 \\
\hline & & Number of trains per hour & 25 & 13 & 12 & 12 \\
\hline
\end{tabular}

trains in order to satisfy the needs of passengers. The organization of trains can be realized with available rolling stocks.

\section{CONCLUSIONS}

This research has elaborated a combined simulation-optimization model for determining the optimal scheme of movement of trains on the metro. A simulation model of Sofia metro has been developed with Arena software. The simulation model was used to observe passenger flows and the movement of trains. It has been used to determine the necessary frequency of service of trains by section in metro network. In the study this relationship is used as a restrictive condition in the elaborated linear optimization model by the criterion of minimum covered train-kilometres so that the optimal number of trains on routes within the metro network can be determined. The relationship can be used also separately for preliminary and operational calculations, concerning the organization of movement of the trains. In this case the total number of trains by sections is determined. To define the number of trains by routes it is necessary to the elaborated optimization model.

In this research we have elaborated a method for selecting the optimal scheme of movement of metro trains. This method includes the design of variant schemes of train routes taking into account the stations where movement can be reversed; it is used to determine the optimal number of metro trains for each route through linear optimization model; it makes it 
possible to choose the optimal scheme of the movement of trains. The method was employed for two peak periods. The results show the need for 7 additional trains in the evening peak period. The number of trains for the morning peak period is unchanged.

The methodology can be applied to other periods of the day. The methodology can be applied with the expansion of the metro network with additional metro lines as well as in the conditions of metro networks located in different cities of other countries.

The proposed methodology can aid and facilitate the decisions connected to route planning, schedule planning, study of additional routes related to increased passenger traffic, extraordinary situations in stations, and others.

\section{ACKNOWLEDGEMENT}

This research is conducted in relation to the execution of contract № 142חA0019-04" A simulation modelling of technological processes in main metro stations of Sofia metro". The research has been funded by Technical University of Sofia, Bulgaria.

СВЕТАА СТОИЛОВА, АОЦ. А- $\mathrm{p}^{1}$

(Автор за кореспонденция)

E-mail: stoilova@tu-sofia.bg

ВЕСЕЛИН СТОЕВ, маг.инж. ${ }^{1}$

E-mail: stoev@tu-sofia.bg

1 Технически Университет - София, Факултет по транспорт

бул. Климент ОхриАски 8, София 1000, България

\section{МЕТОАИКА ЗА ИЗБОР НА ТРАНСПОРТНА CXЕМА НА МЕТРО ВЛАКОВЕТЕ С ПРИЛАГАНЕ НА КОМБИНИРАН СИМУААЦИОННО- ОПТИМИЗАЦИОНЕН МОАЕА}

\section{PEЗЮME}

ЕАин от основните проблеми, свързани с планирането на организацията на влаковете в метрото, е оптимизиране на схемата на Авижение, която определя маршрута и броя на влаковете. В тази статия, се предлага комбиниран симулационно-оптимизационен модел, включващ четири стьпки. В първия етап се симулира Авижението на влака, за да се изследва интервала между влаковете в зависимост от входящия пътникопоток в станциите. Симулационният модел е разработен с помощта на ARENA софтуер. Резултатите са проверени за алекватност, чрез експериментални наблюдения. Във втория етап, използвайки получените симулации, е изследвана зависимостта между наблюдаваните параметри: входящ пътникопоток и интервал между влаковете. Установена е нелинейна зависимост между интервала на движение, входящия Пътникопоток в станциите и пътниците на перона. В третия етап се определят вариантни транспортни схеми на влаковете в метрото. Четвъртата стьпка преАставя оптималния избор на транспортиране на влаковете в метрото на базата на иинеен оптимизационен модел. Моделът използва регресионната зависимост получена във втория етап. Приложимостта на комбинирания симулационно-оптимизационен модел е показана с пример за Софийското метро за два пикови периоди - сутрин и вечер. Сравнени са резултатите от модела и реалната ситуация. Установено е, че резултатите от модела са сходни с реалната ситуация за сутрешен пиков период, но за вечерен пиков период е необходимо да се увеличи броят на влаковете.

\section{КАЮчОВИ АУМИ}

метро; симулация; ARENA; минейна оптимизация; влак; станция; пътник;

\section{REFERENCES}

[1] Lu F, Tian G, Li X, Song M. The Calculation and Simulation to the Subway Train's Time Interval. Proceedings of the IEEE International Conference on Automation and Logistics. 2008 Sep 1-3; Qingdao, China; p. 19561959. doi:10.1109/ICAL.2008.4636481

[2] Xu X-Y, Liu J, Li H-Y, Hu J-Q. Analysis of subway station capacity with the use of queuing theory. Transportation Research Part C: Emerging Technologies. 2014;38:2843. doi:10.1016/j.trc.2013.10.010.

[3] Lane BW. Significant characteristics of the urban rail renaissance in the United States: A discriminate analysis. Transportation Research Part A: Policy and Practice. 2008;42(2):279-295. doi:10.1016/ j.tra.2007.10.001

[4] Zhang Q, Han B, Li D. Modelling and simulation of passenger alighting and boarding movement in Beijing metro stations. Transportation Research Part C: Emerging Technologies. 2008;16(5)38:635-649. doi:10.1016/j.trc.2007.12.001

[5] Öztürk G. Simulation \& Analysis of Izmir metro transportation system [MSc Thesis]. Izmir: Yaşar University, Department of Industrial Management and Information Systems; 2012 [cited 2016 April 19]. Available from: http://aoner.yasar.edu.tr/wp-content/uploads/ 2012/11/Msc-Thesis_Simulation_of_Metro.pdf

[6] Lee JYS, Lam WHK, Wong SC. Pedestrian Simulation Model for Hong Kong Underground Stations. Proceedings of the 2001 IEEE Conference on Intelligent Transportation Systems; 2001 Aug 25-29; Oakland, CA, USA; p. 554-558. doi:10.1109/ITSC.2001.948719

[7] Martinez FE. Application of SIMAN ARENA Discrete Event Simulation Tool in the Operational Planning of a Rail System. Final report [Internet]. University of Puerto Rico; 2002. [cited 2016 April 19]. Available from: http://prt2.uprm.edu/dde/2001/finalreports02/ francisco_final_report_may02.pdf

[8] Motraghi A. Varbanov Marinov M. Analysis of urban freight by rail using event based simulation. Simulation Modelling Practice and Theory. 2012;25:73-89. doi:10.1016/j.simpat.2012.02.009

[9] Hibino N, Yamashita Y, Kariyazaki K, Morichi S. A study on characteristics of train station passenger flows for train delay reduction [Internet]. Paper presented at: 12th WCTR; 2010 July 11-15 [cited 2016 April 19]; Lisbon, Portugal. 12 p. Available from: http:// www.wctrs.leeds.ac.uk/wp/wp-content/uploads/abstracts/lisbon/general/03106.pdf 
[10] Wei Y, Chen M-C. Forecasting the short-term metro passenger flow with empirical mode decomposition and neural networks. Transportation Research Part C: Emerging Technologies. 2012;21(1):148-162. doi:10.1016/j.trc.2011.06.009

[11] Wang Z, Chen F, Li X. Comparative analysis and pedestrian simulation evaluation on emergency evacuation test methods for urban rail transit stations. Promet - Traffic \& Transportation. 2012;24(6):535-542. doi: http://dx.doi.org/10.7307/ptt.v24i6.1205

[12] Meng M, Shao C, Zeng J, Dong C. A simulation-based dynamic traffic assignment model with combined modes. Promet - Traffic \& Transportation. 2014;26(1):65-73. doi:http://dx.doi.org/10.7307/ ptt.v26i1.1252

[13] Srikukenthiran S, Fisher D, Shalaby A, King D. Pedestrian Route Choice of Vertical Facilities in Subway Stations. Transportation Research Record. 2013;2351:115-123. doi: 10.3141/2351-13

[14] LeeY-J. Mathematical Modelling for Optimizing Skip-Stop Rail Transit Operation Strategy Using Genetic Algorithm. Research report [document on the Internet]. Morgan State University; 2012 [cited 2016 April 19]. Available from: http://ntl.bts.gov/lib/44000/44300/44360/ Mathematical_Lee_1112.pdf
[15] Rossetti MD. Simulation Modelling and Arena. John Wiley and Sons, USA; 2010.

[16] Zhang H, Fang W, Hu Q, Li F. Research on Passenger Flow Model Based on Individual Behaviour in Rail Transit System. 2010 IEEE International Conference on Computer, Mechatronics, Control and Electronic Engineering (CMCE); 2010 Aug 24-26; Changchun, China; p. 405-408. doi:10.1109/CMCE.2010.5610119

[17] Wang X, Chen S, Zhou Y, Peng H, Cui Y. Simulation on Passenger Evacuation under Fire Emergency in Metro Station. 2013 IEEE International Conference on Intelligent Rail Transportation (ICIRT); 2013 Aug 30 - Sep 1; Beijing, China; p. 259-262. doi:10.1109/ ICIRT.2013.6696304

[18] Banks J, Carson JS, Nelson BL, Nicol DM. Discrete-Event System Simulation. Prentice Hall, Inc.; 2010.

[19] Ciuffo B, Punzo V, Montanino M. The Calibration of Traffic Simulation Models. Report on the assessment of different Goodness of Fit measures and Optimization Algorithms. Luxembourg: Publication Office of the European Union; 2012.

[20] Moriasi DN, Arnold JG, Van Liew MW, Bingner RL, Harmel RD, Veith TL. Model evaluation guidelines for systematic quantification of accuracy in watershed simulations. Transactions of the ASABE. 2007;50(3):885-900. 